\title{
UN MAESTRO RUSO RENUENTE A LAS ESCUELAS DEL RESENTIMIENTO
} José Jorge Quesada*

RESUMEN: En este artículo, secundando la moción de H. Bloom, se sostiene que las creaciones de los grandes literatos, aunque necesariamente estén insertas en una cosmovisión particular, trascienden las categorías espacio-temporales y, por tanto, son capaces de interpelar a cualquier hombre, de cualquier época. La literatura es maestra en humanidad. Como ejemplo, se revisa una instancia que lo prueba, Los hermanos Karamazov, de Dostoievski.

Palabras Clave: Escuelas del resentimiento, Dostoievski, El gran inquisidor, las tres tentaciones, Los hermanos Karamasov.
ABSTRACT: In this article, we support Harold Bloom's idea, in which the works of great literaries, though being necessarily included in a particular worldview, transcend the spatial-temporal categories and therefore are able to speak to any man regardless of their time. Literature is the teacher in humanity. A telling example of this is The Brothers Karamazov, by Dostoyevsky.

KEYWORDS: Schools of Resentment, Dostoyevsky, The Grand Inquisitor, the three temptations, The Brothers Karamazov.

* Ciencias Sociales, Universidad Panamericana. 


\section{UN MAESTRO RUSO RENUENTE A LAS ESCUELAS DEL RESENTIMIENTO}

El lenguaje, una hueste de metáforas.

Nietzsche

\section{Introducción}

$\mathrm{E}_{\mathrm{n} \text { varios sentidos, podríamos afir- }}$ mar sin temor a equivocarnos que la cultura posmoderna acarrea en sí varios postulados nietzscheanos. Y la literatura despunta al respecto. Para Nietzsche, la realidad, por su dinamismo intrínseco, es ininteligible para el entendimiento humano. ${ }^{1} \mathrm{De}$ ahí que las categorías a partir de las cuales el hombre comprende el mundo son hechura humana (ficticia), que nada tienen que ver con la realidad. Lo único que el hombre ha logrado construir son bases conceptuales -ideologías-, a partir de las cuales interpreta el mundo (a su manera). Pero Nietzsche

${ }^{1}$ Cfr. Friederich Nietzsche, Cómo se filosofa a martillazos, 2002, Madrid, Biblioteca Nueva, pp. 25 y ss. es un filósofo de la sospecha; como tal, relaciona las ideologías con instituciones humanas, que utilizan su aparato conceptual para perpetrar su poder.

Muchos literatos actuales han asimilado esta concepción nietzscheana; de este modo, se sospecha de las creaciones literarias por la carga ideológica que traen detrás. Harold Bloon matiza estas posturas recelosas - por no decir que las rechaza-y llama a estas teorías de la sospecha "las escuelas del resentimiento". ${ }^{2}$ Estas escuelas, explica, han puesto

${ }^{2}$ Cfr. Harold, Bloom, El canon occidental, 2005, Barcelona, Anagrama, trad. Damián Alou, pp. 23 y ss. El autor tiene una gran intuición al plantear esto. A lo largo de su obra, apuntalará un canon de literatos que han sobrepasado sus categorías espacio-temporales, con lo cual trascien- 
hoy en día en tela de juicio el hecho de que la literatura pueda hablar de la realidad en sí misma, por una sencilla razón, que al expresarse, el escritor está definitivamente inserto en una cosmovisión ideológica. Por ello, al fraguar sus escritos, guarda una intención superior, muchas veces implícita, que denota una apología, por así decirlo, de su modo de entender la vida, una apología de su propia ideología. El escritor no habla, entonces, de la realidad en sí misma, sino del modo en que, con tenor viciado y subjetivo, la interpreta.

Lo que se pretende en este escrito es secundar la moción sostenida por Harold Bloom: los grandes de la literatura, a pesar de estar insertos en una cosmovisión muy concreta y particular, trascienden sus categorías espacio-temporales y, por tanto, cualquier ser humano de cualquier época puede entablar un diálogo con sus textos y puede sentirse interpelado por ellos. Dicho en otras palabras, Bloom pone de manifiesto que la literatura, personificada en sus mejo-

den a su época. Su lista de escritores es discutible, pues, ¿cómo catalogar a unos y dejar de lado a otros? Además, el suyo es un trabajo, a nuestro juicio, excesivamente erudito, con una cantidad abrumadora de datos, que no siempre resultan lo suficientemente consistentes para sostener algunas de las tesis intermedias que plantea. Sin embargo, con sus claroscuros, la intuición bloomeana de fondo, reivindicar la autonomía de la literatura, nos parece sumamente pertinente $y$, sobretodo, verdadera. res expositores, es maestra en humanidad, reveladora inigualable de las distintas facetas del ser humano.

Pero se ha de concretar esto y mostrar al menos una instancia en la que sea verdadero. Los hermanos Karamazov, de Dostoievski, es un ejemplo elocuente al respecto. Por cuestiones de espacio, se revisará principal, pero no exclusivamente, uno de los capítulos de esta gran obra, El gran inquisidor.

Primero, una síntesis del capítulo; segundo, este capítulo es susceptible de múltiples interpretaciones; se mostrarán las implicaciones que ello supone para la tesis central. Finalmente, pese a la multitud de interpretaciones posibles, el texto literario como tal parece alcanzar cierta autonomía espacio-temporal, por lo que no es una mera ideología.

\section{El gran inquisidor}

En el capítulo, Aliosha, el más cándido y religioso de los Karamazov, se encuentra entablando un acalorado diálogo con su hermano Iván, un ateo encarnizado y teórico (esto es, de los que dan razones relativamente sólidas de su ateísmo). Entonces, Iván le dice a su hermano que ha escrito un poema sublime. Acto seguido, Iván principia su terrible narración. Se trata, nada más 
NOTAS

ni nada menos, que de la Parusía, la segunda venida de Jesucristo, supuestamente igual de humilde que la primera. Jesucristo arriba en la Sevilla del siglo XVI, emblema paradigmático de la contrarreforma. A su paso, el pueblo, reconociéndolo, lo alaba piadosamente. De pronto, irrumpe el gran inquisidor, un nonagenario de ojos hundidos y rostro enjuto, pero con una chispa vital desbordante. Sin miramientos, y a sabiendas de quién se trataba, manda apresar al divino visitante. Ya en la privacidad, el inquisidor, terrible, dialoga apasionadamente con Cristo. Le reprocha su error garrafal, califica la redención como un reverendo e irreversible fracaso, y todo por "desoír los consejos". Para entones, Aliosha, bastante inquieto por la espeluznante poesía de su hermano, le replica: "¿Y a qué diantres te refieres con los consejos?". "Ésa, es la parte central de mi argumentación" -responde Iván. Para éste, los consejos son las tres tentaciones que el maligno le propuso a Cristo en su período de preparación en el desierto, justo antes de su vida pública. Estos "consejos" serían la clave interpretativa de la historia humana.

Y prosigue Iván, valiéndose de los labios de su senil inquisidor. La primera tentación fue el ofrecimiento diabólico a Cristo de pan, pues había ayunado por días; Cristo lo rechaza aduciendo: "No sólo de pan vive el hombre". Con ello, apunta el gran inquisidor, "negaste la libertad a los hombres, porque nadie, y Tú lo sabes, puede vivir sin pan". La segunda, Luzbel exige a Cristo que crea que Dios enviará una bandada de ángeles si se arroja al abismo; a lo que Cristo responde: "No tentarás al Señor tu Dios". Con ello, reprocha el gran inquisidor a Cristo en un tono igualmente espeluznante, "mostraste tu excelsitud, pero tuviste al hombre en gran estima, sabiendo que, por el contrario, su debilidad es superlativa; de este modo, dejaste la redención sólo para unos cuantos ultrahombres, a los demás los dejaste indefensos". La tercera tentación se refiere al ofrecimiento del demonio de todas las posesiones de la tierra para Cristo. A lo que Cristo responde: "adorarás al Señor tu Dios y sólo a Él servirás"; sin embargo, en el texto de Dostoievski esta tercera está difusa entre otras muchas reflexiones. Y el gran inquisidor reprocha: "Tú sabías que sólo Tú, hijo de Dios, podías rechazar esto, y quizá unos pocos hombres más, ¿es que sólo viniste a salvar a unos cuantos?". Después de otras reprimendas despavoridas del inquisidor, Cristo le da un beso (¿el de Judas?) a su acusador... ${ }^{3}$

${ }^{3}$ Cfr. Fiodor Dostoiewski, Los hermanos Karamazov, 1989, Santiago de Chile, Andrés Bello, trad. por E. Miró, pp. 307 a 330. ¡Imprescindible leer el capítulo! Esta mínima síntesis resulta paupérrima comparada con la riqueza (sociológica, literaria, filosófica, teológica) del mismo. En esta síntesis las palabras del inqui- 


\section{Querellas hermenéuticas}

El punto es que este pasaje tiene múltiples interpretaciones. Puede tener, por ejemplo, por poner algunos casos, una interpretación cristiana, una interpretación generista, otra anticomunista, etc. Analicemos posibles interpretaciones, partiendo de estas diversas cosmovisiones. Veremos las diferencias que guardan entre sí y, una vez hecho esto, analizaremos sus implicaciones.

Así, con ojos cristianos, la narración resulta escandalosa en grado superlativo (y también vista con ojos anticristianos). En efecto, parecería que el poema estaría insinuando que la misma Iglesia, representada en el gran inquisidor, se tornó del lado del maligno. De otro modo, ¿cómo sacrificar al redentor, ¡a sabiendas!? El mismo anciano lo exclama sin titubear: "Nosotros no estamos contigo [Jesús] sino con él [el maligno] desde hace mucho tiempo ya". ${ }^{4}$ (Y es que la inquisición ha sido, por decirlo de algún modo, el talón de Aquiles histórico de la Iglesia, que ha dado pie a multitud de ataques) ${ }^{5}$

sidor están entre comillas, para facilitar la lectura, pero en realidad se trata de una paráfrasis. Por ello, no se plasma la cita. En adelante, las palabras entre comillas son textuales.

${ }^{4}$ Idem., p. 320.

${ }^{5}$ Aunque, como es sabido, el humo calumnioso de la "leyenda" fue más aparatoso que la lumbre misma.
Estaría insinuando, como piensan los filósofos de la sospecha, que la Iglesia ha mantenido su postura para perpetrar su poderío, independientemente de si sigue sus ideales fundacionales o no; siguiendo el pasaje, evidentemente no. O dicho con palabras del anciano, "¿quién puede dominar las conciencias, sino quien tiene autoridad?" ${ }^{\circ}$ El texto sería, pues, terriblemente escandaloso. Supondría cuestionar la veracidad de la Iglesia que el mismo Cristo fundó. Por ello, Aliosha, al terminar la narración su hermano, le increpa: "ello es imposible, porque tu inquisidor no cree en Dios".

Bajo otra visión, esta vez la de un ex comunista (un desertor), el poema podría ser interpretado como una profecía sutilísima. En efecto, imaginemos que esto lo hubiera leído un ruso en los 60's, hastiado de la tiranía comunista. ${ }^{8}$ Probablemente habría interpretado el poema como una premonición prístina (en tanto que fue escrita con casi un siglo de antelación) de su escenario entonces presente: el gran inquisidor fácilmente se amolda a las características de Stalin. No en balde la novela de Dostoievski fue prohibida en Rusia en aquellas épocas. Esta interpretación es más evidente si consideramos otros fragmentos del

${ }^{6}$ Ibid., p. 321.

${ }^{7}$ Ibid., p. 328.

${ }^{8}$ No tiene que ser un ruso. Pensemos cómo habría interpretado Orwell, autor de La rebelión en la granja y 1984, este pasaje del ruso Dostoievski. 
NOTAS

texto que no figuraron en nuestra síntesis. Por ejemplo, después de la primer tentación, la del pan rechazado por Cristo, el inquisidor señala que no podía liberarse el hombre del pan, "y Tú -dice a Jesús- se los arrebataste. Nosotros, en cambio, se los daremos, y entonces serán felices". Y continúa: "les quisiste dar una libertad inalcanzable para ellos, porque sin pan no pueden vivir, entonces los hombres nos dirán: 'reducidnos a la esclavitud, pero dadnos de comed". 9 Y prosigue el infame inquisidor: " $y$ los quisiste libres para elegir entre el bien y el mal, pero ¿qué no te dabas cuenta de que los hombres llevan más paz si no eligen, y por ello prefieren que alguien más les instruya? Nosotros -argumenta- haremos felices a los hombres, y entonces acabarán las sublevaciones. Contrario a lo que Tú enseñas, les permitiremos pecar, pues sus pecados les remuerden, pero ellos no pueden evitarlo, por eso se los quitamos. Les mostraremos así que la felicidad infantil es la más deleitosa", ${ }^{10}$ además "¿quién puede dominar sino quien posee las conciencias y tiene el pan?" 11 Como apuntalábamos, seguramente un ex comunista vería pintadas en el texto muchas de las promesas que en otro tiempo se le propusieron y de las que estaba muy

${ }^{9}$ Cfr. ibid., p. 315.

${ }^{10} \mathrm{Cfr}$. ibid., p. 323.

${ }^{11}$ Ibid., p. 321. distante, pues ¿acaso no fue el comunismo un gobierno paternalista que: 1) daría todo a los hombres -distribuiría los alimentos y los bienes-, y que 2) disolvió la ética clásica y la judeo-cristiana -"les permitiremos pecar"-, en virtud de todo lo cual "cesarían las sublevaciones" y haría del mundo una felicidad perpetua, esto es, "el Cielo en la tierra"? Es evidente, pues, que ver en el inquisidor una premonición prístina de los dictadores comunistas del siglo XX concuerda bastante con el texto.

Otra interpretación posible es la generista. ${ }^{12}$ Una persona generista podría enardecerse al leer este texto. El punto decisivo, el que probablemente más los aguijonearía, sería aquel del beso de Cristo. Notemos que, después de la crispante perorata del inquisidor, Cristo lo besa "en el labio". ${ }^{13}$ En el siglo XIX esto quizás hubiera extrañado un tanto, pero dadas las circunstancias ello estaría justificado: ¡un inquisidor ( cristiano!) estaba a unos minutos de matar a Jesús, a sabiendas! Cristo debía valerse de algún elemento más que el beso de Judas, para estimular el arrepentimiento del inquisidor, porque éste estaba cierto de que Él era Dios. Pero un generista del XXI, al leer el texto,

${ }^{12}$ Entendemos aquí por generista aquel feminismo a ultranza (en realidad no es feminismo) que niega la naturaleza humana y hace de ella una construcción cultural. Cfr. Jorge Scala, Género y derechos humanos, 2004, Buenos Aires, Promesa.

${ }^{13}$ Ibid., p. 328. 
probablemente haría de Cristo "el primer gran generista", como contrapartida del crispante y deleznable inquisidor. Cristo sería el primer gran open mind de la historia. Pero en fin, sólo es una interpretación posible.

Ahora bien, hemos dibujado tres posibles interpretaciones. La cuestión es, ¿qué implica esto? ¿Qué significa que una narración literaria sea susceptible de un sinnúmero de interpretaciones? A nuestro juicio, ello conlleva implicaciones muy grandes. La más importante, que la realidad sería ininteligible desde la literatura. Pero expliquemos esto por partes. En primer lugar, habría que considerar que todas las interpretaciones suponen entender un contenido dependiendo de la perspectiva desde que se mire el texto. Así, como los intérpretes tienen una cosmovisión particular, entonces difieren entre sí las interpretaciones de un mismo texto. Cada quien interpreta el texto según el color de los lentes que porta. Pero el punto es más radical aún. El autor, Dostoievsky, tiene una filosofía particular, a partir de la cual interpreta la realidad y la deja plasmada con su pluma. Así, parecería que todo acto de quien se acerca a la literatura es una interpretación, una metáfora de una hueste de metáforas. En efecto, ¿acaso el lector no desdibuja el texto en sí mismo al interpretarlo? Más aún, ¿no desdibuja un escritor la realidad misma, al conocerla desde sus categorías ideo- lógicas? Así las cosas, resulta que el acto de lectura literaria no es más que una interpretación fantasiosa-el acto del lector-, de una concepción fantasiosa y metafórica de la realidad -el acto del escritor. De esta manera tan drástica, la consecuencia inevitable es un escepticismo profundo. Nadie podría arrogarse como un conocedor de la realidad ( $i y$ menos de la realidad humana!), por medio de la literatura.

En resumen, la realidad sería verdaderamente ininteligible desde el acto literario. Y la literatura no sería sino una actividad aprisionada en las celdas espacio-temporales, tanto de quien la escribe, como de quien la interpreta.

Consecuentemente, considerando esto desde la óptica de las "escuelas del resentimiento", la literatura nada tendría que decirle al hombre de las distintas épocas. Una lectura literaria exaltaría los ánimos de algún lector, en tanto que él supondría entender algo de la realidad, pero sería un iluso que yerra: sólo "entiende" (mejor dicho, mal entiende) una ideología particular, la del escritor.

La consecuencias no son, pues, nada triviales. Sin embargo, ¿realmente el texto literario está atrapado en la interpretación, con lo cual el deleite del lector, al enfrentarse a un texto, poco tiene que decirle realmente a sí mismo: la lectura no le serviría para conocerse a sí mismo, para explorar su yo interior mediante la narración literaria, o por el contrario, los grandes 
NOTAS

textos literarios tienen algo que decirle a un hombre de cualquier época, de cualquier parte, en tanto que alguien podría conocer mejor su interioridad y el drama de la existencia humana leyendo a un gran literato? Nosotros sostenemos la segunda opción. En nuestra opinión, una gran obra literaria trasciende las categorías espaciotemporales y, consecuentemente, una persona puede ser interpelado por ellos. Pero hay que matizar bien esta tesis.

\section{Alusiones reales}

La cosmovisión del autor y del lector

Para empezar, hemos de reconocer que, en efecto, un maestro de las letras, un gran escritor, está "atrapado" en su visión particular, y ello condiciona, más aún, determina, sus escritos en gran medida. Un ejemplo, el mismo Dostoievski. Es un autor que primariamente era socialista. Sin embargo, tras pasar ocho años de cautiverio en Siberia, entre la escoria rusa, y contando con los Evangelios como único libro de meditación, se convierte al Cristianismo. La experiencia dramática de estos años se verá reflejada como en un espejo en sus escritos.

Lo mismo podemos decir del lector. Está sujeto a comprender la narración desde su aparato conceptual. Pero ello no niega, sostenemos, que las grandes obras interpelen al hombre de algún modo.

Pero vayamos al texto. Si leemos Los hermanos Karamazov con la óptica de la sospecha-la de "las escuelas del resentimiento"-, veremos en Dostoievski a un autor apologeta de su visión cristiana, pero que también trasciende la mera cosmovisión. Por ejemplo, un pasaje esencial de la novela, en que concurren los Karamazov: el padre, Dimitri, Iván y el pequeño Aliosha. Se trata de las partes iniciales de la novela, en la que todos convergen en el monasterio, con el eremita Zósimo. Ahí, Piotr, un personaje que interactúa con ellos en la escena, rememora unas frases altisonantes, dichas por Iván dos días antes:

Nada en el mundo obligaba a la gente a amar a sus semejantes; ninguna ley obligaba al hombre a amar a la humanidad; si el amor había reinado ahora sobre la tierra ello se debía, no a la ley natural, sino a la creencia en la inmortalidad [...] esa es toda la ley natural. De modo que si se pierde la fe en la inmortalidad se perderá no sólo el amor, sino las ganas de continuar en este mundo. No habría nada inmoral, todo estaría autorizado, hasta la antropofagia $[. .$.$] todo debe convertirse en lo$ contrario a la ley religiosa; así el egoísmo debe convertirse en ley necesaria, no solamente en lo más razonable sino hasta la más noble. ${ }^{14}$

${ }^{14}$ Op. cit., p. 94. 
Visto con el tenor de la sospecha, se pensaría que el autor está queriéndonos persuadir de su ideología, diciendo algo así como: "paganos, jay de ustedes si quieren suprimir a Dios de la sociedad, la inmortalidad, todo se convertirá en una selva!", pues "si Dios no existe, todo es posible, ¡hasta la antropofagia!" No sabemos si Dostoievsky tendría esta intención con el pasaje, o con la novela misma: quizá sí.

Lo sustancial es que independientemente de la intentio auctoris y su ideología, el pasaje (y toda la novela, porque este pasaje es premisa esencial del parricidio posterior), trae una cuestión radicalísima, a saber, si la ética (más genérico aún, si el comportamiento) está vinculada con Dios o no, es decir, en qué manera nuestro desenvolvimiento existencial se relaciona con Dios: si hay designios divinos para el hombre. Se lo han preguntado hombres en todas las épocas de la historia y de todas las culturas. Desde Grecia a la insigne Tenochtitlán, desde la antigua Persia, hasta el Cristianismo y el Islam de la nueva era. El ser humano es un ser religioso, porque ahí donde se encuentran vestigios de humanidad se han hallado vestigios de religiosidad..$^{15} \mathrm{Y}$ una nota esencial de la religiosidad es la

${ }^{15} \mathrm{Cfr}$. Aurelio Fernández, El hecho religioso y el hecho cristiano, 1988, Madrid, Dossant, pp. 55 y ss. manera en que el comportamiento de un ser inferior -el hombre-se vincula al del ser superior-Dios o dioses o tótems, etc. ${ }^{16}$ De estas premisas se puede concluir, no que exista Dios o que debamos ordenarnos a su designio, sino que realmente en todas las épocas la cuestión de la relación hombre-Dios ha estado a flor de piel. Y el texto dostoievskiano, encarnado en un escenario particularísimo, se suma a la discusión. La cuestión de la relación Dios-hombre-comportamiento es milenaria, ya sea que al tomar postura unos se decanten por la ratificación de tal vínculo, y otros para negarlo, es ineludible. Cualquier persona, de cualquier época, puede leer este pasaje, apasionado y vivaz, y encontrarse con una cuestión importante, y sentirse interpelado. De esta manera, aprende, se enriquece por la literatura. El texto ha trascendido las categorías espacio-temporales en que fue escrito $y$ ha dado un salto (¿a la eternidad?), para decirle algo al lector que lo lea. El texto se libera, de alguna manera, de la ideología de su propio autor.

Así las cosas, vemos que la encendida pluma de Dostoievski pintó para siempre una cuestión que: 1) sus antecesores se preguntaron; 2) sus coetáneos discutieron; 3) nosotros ahora discurrimos; y, 4) nuestros sucesores debatirán. La literatura sí tiene algo que decir. Es maestra en humanidad.

\footnotetext{
${ }^{16}$ Idem, p. 34.
} 
NOTAS

\section{Otros ejemplos}

Retomando el pasaje de El gran inquisidor, el fragmento de la tentación del pan, en que el inquisidor reprocha a Cristo por rechazarlo, tiene diversas interpretaciones. La cuestión universal que, no obstante, tiene de fondo es la de si el hombre está sujeto a la materia o no. En efecto, Cristo negó el pan, y arguyó que "el pan no sujeta al hombre". El hombre no es consumista por necesidad; para Cristo, el hombre es, cualitativamente hablando, un espíritu encarnado, pues de no haber cierta espiritualidad, abandonar "el pan" sería imposible. Sin embargo, podría haber opiniones encontradas al respecto. Lo relevante para la tesis es que esto no fue cuestión de Jesús únicamente: eso mismo se lo plantearon los indios, liderados por Gandhi, al hacer de la hambruna su instrumento liberador; es lo que nos preguntamos nosotros cuando vemos la indigencia espiritual y la miseria de algunos países que elogiosamente denominamos "de primer mundo", donde proliferan los suicidios. El tema, por tanto, no incumbe a una cosmovisión particular (ni del autor, ni del lector), sino a todo ser pensante. La cuestión ¿el hombre está sujeto a la materia necesariamente? es universal, pero pintada literariamente le añade una vivacidad y una elocuencia, que nos permite "acariciar" o "rasguñar" la realidad humana. La literatura es la contemplación cercana del misterio humano. Entonces, algo podemos aprender de la buena pluma de los grandes escritores, nos avengamos a las razones de sus ideologías o no.

Otra de las muchas cuestiones universales que trae a cuento Dostoievski en su narración es la del perpetuo tema de la redención del hombre. En el gran inquisidor se refiere a la redención de Cristo (o la comunista, si con esos ojos se lee). Pero trae a cuento la redención, tema que a nadie es irrelevante. En efecto, podemos pensar que la redención viene de Cristo o no; en la visión marxista, la redención definitiva vendría de un Estado comunista, liberado al fin de las clases sociales; un moderno ilustrado atribuirá tal papel a la ciencia y al progreso; un surrealista la pondría en el arte. Lo que el texto pone en cuestión es si el hombre se basta a sí mismo o no. Insistimos, se puede pensar que el hombre sí se basta a sí mismo; pero la cuestión no es indiferente, pues todos nos hacemos esta pregunta, de manera velada o explícita, formulada de esta manera o de otra. De este modo, una vez más, este magnífico maestro ruso nos ha interpelado en los recovecos más íntimos del alma, como lo hizo con sus coetáneos y lo hará con los que nos seguirán. 